\section{Category}

\section{Synthesis of}

Heterocycles

\section{Key words}

\section{bromination}

iodination

rhodium catalysis

directed catalysis

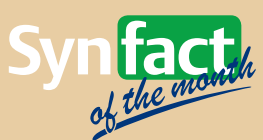

\title{
Rhodium-Catalyzed Directed Halogenation of $\pi$-Excessive Heterocycles
}

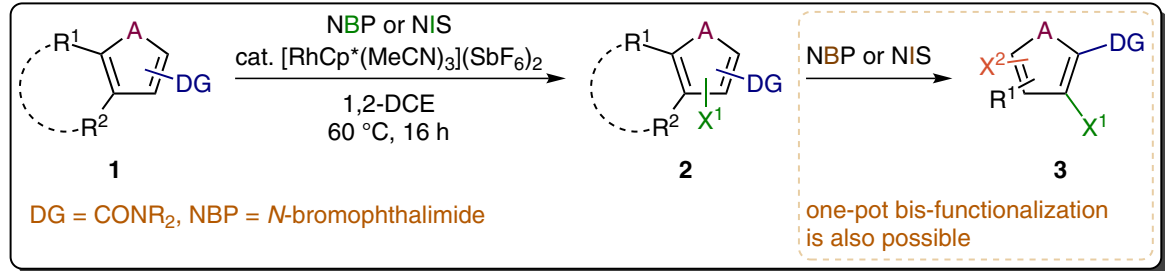

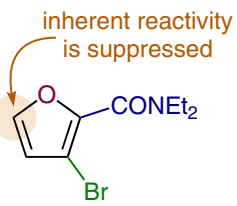

2a: $92 \%$ yield $(10 \mathrm{mmol}$ scale $)$

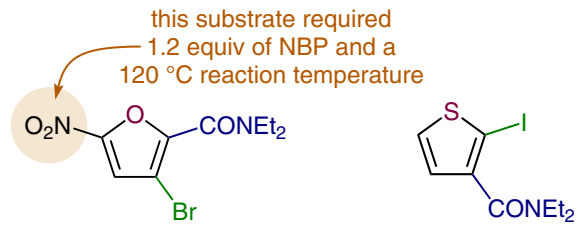

2b: $57 \%$ yield

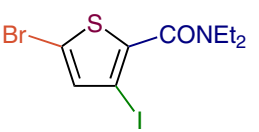

3a: $80 \%$ yield

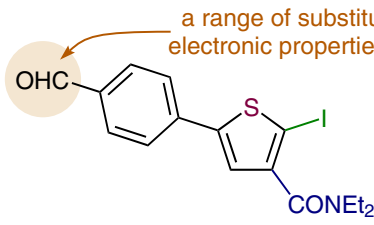

2d: $96 \%$ yield<smiles>COC(=O)c1c(Cl)oc2ccccc2c1=O</smiles>

2e: $73 \%$ yield

the scope was extended to a smal number of six-membered heterocycles

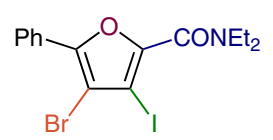

3b: $85 \%$ yield
Significance: The bromination and iodination of $\pi$-excessive heterocycles 1 under directed rhodium(III) catalysis is reported. The reaction provides an orthogonal approach to electrophilic halogenation, overriding the inherent reactivity of the starting materials. Additionally, the method is complementary to directed ortho metalation, which can afford similar products (2 and $\mathbf{3}$ ) without the need for a heavy metal catalyst, but under strongly basic conditions (e.g., see: E. G. Doadt, V. Snieckus Tetrahedron Lett. 1985, 26, 1149). Bis-halogenated products $\mathbf{3}$ were also obtained from compounds 2 in a one-pot process by addition of a second equivalent of the electrophile. The reaction was reported to proceed efficiently under air and without special precautions to exclude moisture.

SYNFACTS Contributors: Victor Snieckus, Benjamin N. Rocke (Pfizer) Synfacts 2015, 11(4), 0366 Published online: 18.03.2015 Dol: 10.1055/s-0034-1380373; Reg-No.: V02815SF
Comment: The scope and functional group tolerance of the reported reaction were demonstrated to be broad, with a range of substituted five- and six-membered heterocycles being demonstrated. However, the viability of directing groups other than dialkyl amides would have provided welcome generality. Kinetic studies demonstrated a dual role for the rhodium(III) catalyst, whereby it additionally functions to suppress the inherent reactivity of the heterocycle. $\mathrm{AgSbF}_{6}$ was also observed to suppress the innate reactivity, and in its presence, the catalyst loading could be decreased to $0.1 \%$. Additional mechanistic evidence showed that $\mathrm{C}-\mathrm{H}$ bond activation is turnover limiting but electrophilic aromatic substitution and concerted metalation-deprotonation mechanisms could not be distinguished. 